\title{
Transformações societais e mutações dos sistemas educativos e culturais: abordagem comparativa Oriente/Ocidente ${ }^{1}$
}

\section{Societal transformations and mutations of educational and cultural systems: comparative approach East/West}

\section{GEORGES BERTIN}

CNAM do Pays de la Loire.

<georges.bertin49@gmail.com>

\section{RESUMO}

As sociedades da Vila Planetária estão, hoje, em confronto com mutações rápidas e irreversíveis. Elas questionam, de forma dramática, as relações dos sistemas educativos em seus ambientes sociopolíticos.

Após a passagem de sociedades tradicionais marcadas pela ideia de comunidade e ordenadas pelos códigos da logosfera, aquelas da Modernidade sustentadas pelos Estados Nações e pelos referentes de uma graphosfera, a organizadora de toda a vida cultural e institucional, nós vivemos, de agora em diante, uma nova transformação numa Pós Modernidade, as múltiplas referências na pluralidade dos modos de pertencimento e de expressão, acelerados pelas redes no momento da Galáxia Internet.
Com isso em mente, a questão das relações Oriente/Ocidente é, talvez, uma das possíveis possibilidades de leitura para repensar a edução como sistema cultural e intercultural.

Examinaremos, nesse sentido, a ruptura epistemológica do final do século 12, quando "o Ocidente escolhe seu destino fastiano" (Durand) e com base nas nossas análises sociais, antropológica e contemporânea, tentaremos alojar a relação com as rupturas atuais que encontramos na esfera social, nos códigos e nas linguagens para mostrar as implicações nos imaginários sociais em ação, entre o Oriente e o Ocidente, os quais nos obrigam a repensar os sistemas educativos agora no plural.

Palavras-chave: Educação; Sociedades; Imaginários; Comunicação; Oriente; Ocidente. 


\section{ABSTRACT}

The societies of the village planet are today confronted with fast and irreversible changes. They interrogate so radically, the relations of education systems with their sociopolitical environments.

After the passage of traditional societies, marked by the community ideia and ordained by codes of logosphere, for those of Modernity, sustained by the relationship with States Nation and sorted by codes of logosphere, for those of Modernity, sustained by the relationship with the United Nation and the related grafosfera organizing a lifetime of intellectual and institutional, we live now, a new mutation in a postmodernity of multiple references, in the plurality of ways of belonging and expression, accelerated by the networks in the time of galaxy internet.
In that spirit, the question of relations East/West is perhaps one of the possible keys to rethink the education system as cultural and intracultural.

We shall examine, in this sense, the epistemological rupture of the end of the XII century, when "the West chooses his destiny Faustian" (Durand), and, based on the analysis of contemporary socioantropology, try to establish in relation to contemporary breaks that found in the social sphere that of the codes and languages to show their implications on social imaginaries in action, between East and West, which force us to reconsider now plural educational systems.

Keywords: Education; Societies; Imaginaries; Communication; East; West.

O Oriente ilumina o Ocidente que reflete a luz recebida."

Marie-Jo Delalande

As culturas não são sistemas fechados e autóctones... elas são, por sua vez, abertas e algumas vezes dilaceradas pelos caprichos da história."

Gilbert Durand 
tradição e ducativa no sentido de "condução fora de", do latim e ducere, nos faz sair Ada postura do crente servil substituindo-a por um metaconhecimento. O método, meta ôdé, "colocação no caminho", propõe, na verdade, itinerários que constituem um contra modelo, próximo daquele que propõem, há milênios, as sabedorias orientais. Ele encontra singularmente sua atualidade em um mundo fadado à insignificância generalizada. Após contextualizar as evoluções societais das quais somos testemunhas, ao mesmo tempo, como educadores e atores, mostramos aqui os pontos de encontro entre Ocidente e Oriente, exceto transmissão, e os estudamos mais particularmente sobre a questão educativa.

\section{Contexto, evoluções e mutações societais}

David Riesman² (1984) distingue três tipos de sociedades, tipos para nós operacionais para compreender as mutações comunicacionais e educativas em questão:

1) tradition directed (determinações tradicionais);

2) inner-directed (introdeterminada);

3) other-directed (extradeterminada).

\section{As sociedades de determinação tradicional (tribais ou primárias)}

Essas sociedades são caracterizadas por Riesman (1984), como um forte potencial de crescimento. Sua civilização, fundada num deserto econômico, tende a ocupar e a direcionar o mundo numa perspectiva de estabilidade através de calendários e ritos religiosos, na recorrência e ciclicidade das formas estabelecidas. Seus membros seguem a tradição definida de tempos imemoriais, mantendo relações funcionais bem estabelecidas com o meio ambiente graças aos rituais que os dão forma. Como o indígena, escrevia Lucien Lévy Bruhl (1976), "que seria o seu destino individual quando ele jamais pensou a independência de sua pessoa na sociedade onde ele vive?". 
As sociedades tradicionais conhecem, entretanto, uma implacável e incessante autoalteração, mesmo que achamos difícil compreender, ela se desenvolve em suas profundezas. Seu caráter estático, repetitivo, ahistórico, atemporal, somente é a sua maneira de relação com o tempo, a uma temporalidade diferentemente histórica pois "toda sociedade existe instituindo o mundo como o seu mundo" (1976, p. 259). Elas estão, entretanto, "igualmente envolvida na história no sentido de que a passagem do tempo as marca e as transformam, mas elas sofrem essa transformação sem tentar controlá-lo" (Cazeneuve, 1991, p. 104). Podemos discutir com Jean-Charles Pichon a relação com o Grande Tempo, o tempo dos deuses, dos mitos que dominam as épocas e, nos quais, ele observa a ciclicidade, lei do Eterno Retorno, que as situa além dos tempos históricos e dos quais as sociedades tradicionais seriam testemunhas privilegiadas.

Sociedades próximas da Natureza e de seus ciclos, elas marcam um esforço de solidariedade entre seus membros com base no local de habitação e trabalho (Castells, 2001). Sendo o laço social predominante este da grande família estendida, a tradição aqui reina como modelo de conduta educativa e as organizações sociais se regulam entre o patriarcado e as relações tribais e familiares (Castells, 2001) encarregadas de assegurar a reprodução do mesmo.

A evolução será lenta em direção à fase seguinte, não-linear, já que em diversos lugares, inclusive nas sociedades contemporâneas, subsistem comportamentos dentro deste modo de funcionamento social. A relação com o coletivo está presente em todas as formações sociais da Idade Média, período obcecado pelo coletivo, pelo grupo comunitário, a aldeia, os pertencimentos, onde o trabalhador isolado só faz errado e onde o grande "pecado" consiste em se singularizar (Le Goff, 1964). De fato, o indivíduo medieval preso em uma rede de solidariedades e também de submissões, mal encontra sentido em sua liberdade ou, mais exatamente, a confunde com os 
privilégios que garantem seu status. Como a liberdade é indissociável da comunidade, ela só pode existir na dependência e na contra dependência.

Isso era verdade tanto nas comunidades rurais, onde a proximidade acarreta ipso facto a fraternidade e a communio ou a comunidade, como no meio urbano, onde a cidade ocidental vê organizar-se corporações e confrarias, onde a catedral, casa comum, é a professora do povo.

Ainda encontramos este funcionamento na órbita da grande área das catedrais, com os compagnons-bâtisseurs ${ }^{3}$, que devem afirmar sua solidariedade, fazer visitas em caso de doença e prestar assistência mutualmente, graças a fundos de ajuda.

Suas modalidades de comunicação estão ancoradas em uma relação com o sagrado marcada pela predominância do logos divino (em suas diversas manifestações) e por saberes baseados na onipotência da palavra, revelada em universos platônicos onde as ideias precedem as coisas e sua expressão. Em certas tradições educativas, a palavra é faculdade de meditação sagrada, ela se confunde com um sopro divino, o poder criador de Deus, como o exemplo do logos grego e do verbum dos padres da Igreja. É assim que, no Antigo Testamento, a pluralidade das línguas foi instituída por Deus como castigo ao excesso dos homens (simbolismo da torre de Babel fundada por Nemrod). Uma tradição muçulmana menciona igualmente a relutância de Ali em rezar sobre suas ruínas. Para os druidas, nos ensina Christian Guyonwarc'h (1986), havia três tipos de glam dicinn: encantamentos ou gritos, maldições improvisadas e extremas para a injúria, vergonha ou culpa, que baseavam sua eficicácia - tamanho era o poder da palavra do druida - sobre a magia do verbo, ao mesmo tempo em que eram munidas de um dispositivo ritual tão quimérico quanto considerável. E a educação druida também é baseada na repetição e na transmissão oral.

O nível de comunicação cultural é ao mesmo tempo plano e recorrente, o homem tem aí pouca consciência de sua qualidade de indivíduo. Palavra toda poderosa, 
linguagem santificada, o espírito humano recebe sua manifestação via voz do eterno (Debray, 1969), toda revelação sendo primeiramente oral e inspirada divinamente, de forma direta ou através de um anjo (Moisés no Monte Sinai, o Profeta Mohamed em Meca, Jesus sobre a montanha, etc.).

A serviço desse meio, a escuta seria privilegiada como sentido físico e vetor de uma comunicação essencialmente oral. Primeiramente circular, ela é baseada no compartilhamento fusional das emoções e no sentimento de que, cada um sendo parte indistinta do todo, o real só é evocado na repetição da certeza do retorno das coisas a seu lugar esperado, as invocações e rituais servem para comunicar sua lembrança.

A ruptura com o período renassentista e o acesso à modernidade se manifesta pela predominância da escrita. O historiador Martin Aurell (2011), ao estudar a classe instruída, nos mostra que nos séculos XII e XIII, "a oralidade no estado quimicamente puro não existe".

Se o livro - ainda restrito em número - tende a se expandir na sociedade da época, via as scriptoria dos monastérios e também as bibliotecas nobres, a proporção de indivíduos analfabetos continua grande e a voz ainda é o maior vetor de divulgação ao público das obras escritas ou nas palavras recitadas pelos malabaristas nas assembleias curiais. Isso é verdade para o livro de ficção lido em voz alta, como para o ensino universitário, onde o professor lê e comenta as obras, e onde os estudantes aprendem a argumentar graças à disputatio.

Para tanto, a mudança que acontece entre a oralidade e a literatura é favorecida pela difusão das línguas vernaculares (romanas). Da mesma forma, certos abades abraçarão a tarefa de "traduzir" os textos sagrados ou religiosos para a edificação daqueles "que não têm clérigo". A presença das letras contribui para amenizar a brutalidade cavalaresca, favorecendo a erudição (no sentido etimológico, i.e. extrato da rusticidade, da grosseria), e a culura livresca cristaliza, nessa época, um encontro 
intelectual entre diversos tipos de interesses (Aurell, 2011). Al Andalus segue, em nossa memória coletiva, um dos locais desta confrontação/fusão.

É neste período, que Durand faz coincidir com a morte de Averróis, em 1198, que foi assassinado Sohrawardi e que o grande Ibn Arabi, deixando Córdoba, retorna ao Oriente. Face à Teosofia da Luz, o Ocidente escolhe seu destino faustiano (Durand) quando sua epistemologia totalitária, codificada pelo realismo crítico, confunde a causalidade com um tempo abstrato, newtoniano e sideral, quando nasce a fábula de uma história linear, única e causal. Se oficializa, então, a separação do corpo e da alma, alinhando o corpo e, depois, o espírito humano sobre a máquina, uma lógica estritamente binária que vem a substituir o "sistema unitário e trinitário da relação simbólica do sistema das assinaturas, o signo algébrico transparente substitui então o símbolo e sua opacidade constitutiva" (Durand, 1979, p. 74).

Redução do sagrado ao profano, supremacia da explicação histórica, a onipotência dos fatos, se impõem no pensamento moderno. Elas formarão a base de toda Educação. A Ciência Moderna, incluindo a ciência política, nasce com base na filosofia dualista.

\section{As sociedades introdeterminadas, sociedades industriais ou secundárias}

Para David Riesman (1984), essas sociedades (pré-industriais e industriais) se caracterizam por uma velha classe média formada pelas profissões do banco, do comércio, da empresa em expansão quase constante:

- seja intensiva, em bens e pessoas;

- seja extensiva, nas suas capacidades de explorar, de colonizar (cf. as grandes descobertas).

Sociedades imperialistas, suas dinâmicas internas são orientadas para objetivos gerais, tidos como inevitáveis. As escolhas são determinadas por um caráter rígido, mas altamente individualista, cada um acredita ter consciência de dirigir sua existência, 
que suas escolhas são amplamente abertas. O âmbito social é restritivo, um indivíduo tem poucas possibilidades de reconsiderar sua decisão, mesmo com a solidariedade em acentuado declínio no perído precedente, o que poderia levar à anomia (Durkheim). Esta sociedade encontra seu apogeu no classicismo, período que amplia a ordem, a regra, a autoridade, o triunfo da razão, da lógica, que proíbe a mistura de gêneros, exaltando a majestade do tom, a verossimilhança. As qualidades desenvolvidas são a razão, o discernimento, a objetividade, o "senso prático", abrindo caminho para as técnicas e tornando-se o modelo absoluto. Nela, a dialética funda o mito do progresso, já que sempre há uma superação possível.

O nível de comunicação cultural é unidimensional e fechado, tudo voltado à primazia de um individualismo dominante (os artistas já assinam suas obras). Ele constitui o substrato cultural paradigmático da modernidade e preside a crescente diversidade dos modos de sociabilidade em uma centralização no indivíduo que favorecerá o desenvolvimento da família nuclear.

Enquanto a sociedade tradicional se baseava na oralidade (logosfera, de Debray), esta vai focar a comunicação entre os indivíduos na escrita, no livro, em seguida amplificada pela imprensa e que cria, pelo recurso da fragmentação, um outro modelo de episteme em um Ocidente homogeneizado. Ela será o principal suporte da Educação. Esta, para McLuhan (1968), tem um papel primordial na transformação social, impondo a linearidade do raciocínio, o qual é organizado pela onipotência da programação dos caracteres e subordina os mecanismos da compreensão à visão, sentido primeiro neste contexto. É o que McLuhan (1968, p. 71) chama de "explosão do olho", este transporte da escuta à vista sendo, para ele, uma das transformações mais fundamentais e radicais que possam ter acontecido na estrutura social. Nos processos de aquisição e de comunicação a imagem será, sempre, subordinada ao texto, ela o acompanhará, o ilustrará. 
Edgar Morin (1984) descreveu os códigos constitutivos que se baseiam na dupla conhecer/se expressar e que fazem a cama sutil do elitismo em suas práticas monopolistas.

Este double-bind, vivido na divisão entre esses tipos de formas, vai facorecer a emergência de um novo tipo de cultura, que desestabiliza as normas e os códigos da cultura então cultivada. Um novo sistema emerge enquanto procura seus modelos em outros lugares.

McLuhan (1968) analisou muito precisamente a junção desta sociedade e a que irá segui-la a nossa constatando que o individualismo visual, alfabético e fragmentário não mais é possível em uma sociedade eletricamente estruturada e fragmentada.

\section{As sociedades extradeterminadas (submetidas às preferências de outrem), pós-modernas ou terciárias}

New perspectives give birth to new historic ages. Humankind has many dramatic revolutions of understanding - great leaps, sudden liberation from old limits."

(Marylin Ferguson)

E eis que mais uma vez nós visamos outros tempos, uma nova era da humanindade. Chega, de fato, uma mudança de perspectivas, de horizontes culturais, devido às misturas de populações, às mestiçagens. A redescoberta do pensamento selvagem, do arkhé, é o primeiro fator e se enquadra, para Claude Levi-Strauss, na perspectiva de uma ruptura quádrupla: com o Humanismo e a ideologia do sujeito; com o pensamento evolucionista e historicista, enquanto "as construções do mundo moderno", escreve Pierre Chaunu (1982, p. 16), "realizaram um progresso decisivo na ordem da 
abstração"; com o atomismo, que considera os elementos independentes da totalidade, e McLuhan (1968) também enfatizou que o alfabeto fez nascer os civilizados, ou seja, indivíduos distintos e iguais perante a lei escrita, porque ele produz uma dissociação analítica dos sentidos e das funções; e com o empirismo, quando o vivido é repudiado em benefício da língua e dos sistemas de relações que permitem uma compreensão de todos os sistemas culturais. Isso o conduz a adotar o ponto de vista do relativismo cultural: nenhuma cultura possui, a partir de então, critérios absolutos que a autorizem a aplicar suas próprias distinções aos produtos de uma outra cultura.

A diferença observável em relação às sociedades tradicionais é a aceleração constatada nas trocas sociais, culturais e educativas. Sociedades singulares, escreve Maffesoli (2000), cuja singularidade é enraizada em um substrato arcaico atemporal repensado em função do presente. Vivida de maneira específica, ela não guarda a menor memória das origens.

Trata-se, para Riesman (1984), de sociedades em declínio demográfico, compostas, majoritariamente, das novas classes médias facilitadas das grandes cidades. Observamos nelas uma mudança de mentalidade, de valores. Seu universo interno estreitado provoca:

- uma aceleração dos contatos entre as culturas, a difusão de modelos educativos baseados na interação, principalmente digital;

- a implementação de novos mecanismos psicológicos, ligados à abundância, aos lazeres, aos excedentes, ao consumo aumentado de palavras, imagens, signos (desenvolvimento dos meios de massa);

- outros sistemas de relações descritos por Marylin Ferguson. Baseados nas novas redes relacionais, como "sinérgicas, holísticas, abertas ao mundo, à celebração e à exploração, são o local de alternativas sociais que garantem outros tipos de cooperação entre grupos e indivíduos" (Ferguson, 1980, p. 225). 
As atitudes sociais são orientadas pela preocupação de manter contato com os outros de forma quase instantânea para abolir a temporalidade. A sexualidade, separada dos imperativos de produção/reprodução, torna-se um bem de consumo, um mecanismo de defesa contra a apatia, um laço de reafirmação pessoal e busca psicológica. Igualitarismo e uniformização são as suas marcas (Maffesoli, 1979) enquanto o estatuto da mulher tende à igualdade.

A comunicação é determinada pela instantaneidade e a interdependência, sociedades onde o jogo predomina como fator do laço social, se não for uma nova iniciação ao estar-junto (Vincent, 2010), sociedade híbridas, ditas da videosfera ou da numerosfera, onde a comunicação não passa mais de indivíduo a indivíduo, mas da multidão à multidão (Debray, 2000).

Estamos agora na era do terciário, senão do quaternário, da interdependência e das consciências múltiplas em interação. A rede, base da comunicação na aldeia global, reúne gradualmente, nas redes sociais, as novas tribos da internet (Maffesoli, 1988) quando, como viu igualmente Castells (2001), as comunidades tomam formas personalizadas e geram os individualismos em rede, implementando as sinergias, fonte de uma potência societal jamais atingida na História, como pudemos ver recentemente. Numerosas realizações educacionais constituem-se, agora, fora da instituição educativa e isto apesar das tensões observadas.

Volta com força o reino das imagens, mas estas são agora comoventes, díspares, ainda ligadas ao texto, mas não para ilustrá-lo, e, sim, como contraponto, em uma relação dinâmica que não é mais de subordinação (os hipertextos, o multimídia), mas de interação e de interdependência, solicitando ao mesmo tempo vários sentidos: visão, audição, ver e logo tocar, gosto, olfato... como começamos a apreciá-la.

O consumo é, nessas sociedades, a cultura majoritária, de uso, das pessoas comuns e tende a ganhar o planeta incluindo milhares de países menos desenvolvidos (estima- 
se em $50 \%$ por ano o crescimento dos usuários de telefone celular na África Negra e no Maghreb, assim o número de telefones celulares supera, hoje em dia, no Marrocos, em unidades, o número da população do Reino ${ }^{4}$ ). De fato, pela sua manipulação do produto, o praticante é o autor de uma produção cultural secundária que ele toma para si; de certa forma, ele se autoeduca (Certeau, 1971) e participa, por troca imediata, da educação de seus semelhantes. O aqui e agora é valorizado em detrimento da história por múltiplas estratégias e táticas que fazem com que, de um mesmo objeto, cada um faça um produto para si, diferente. De fato, "a vida imediata se exprime com força, ultrapassa as fronteiras, barreiras e diversas clausuras institucionais, escorre por tudo... testemunhando uma vitalidade sem justificativa ou racionalização alguma" (Maffesoli, 2000, p. 170).

Mais uma vez, escreve Maffesoli, o pensamento oriental pode nos ser útil, em contraponto, quando evidencia a cosmicidade das coisas.

\section{Mutações dos imaginários e o advento da interculturalidade}

McLuhan (1968) nos descreveu uma nova consciência sensorial e instantânea do todo, quando passamos a um mundo de estrutura e configuração o qual ele denomina campo global. Cá estamos, onde a imagem encontra toda sua força, enquanto a modernidade a deixou subordinada ao texto. Não é estúpido perguntar-se a este respeito, sobre a potência dos regimes do imaginário em questão e sua supradeterminação da mutação em que vivemos.

Observamos, a longo prazo, a transição dos modelos do imaginário social, desde as sociedades maternais da logosfera, pensando no retorno do mesmo (tempo cíclico) até aquelas, heróicas, da grafosfera e do progresso, concedendo uma exata definição dos momentos do tempo reforçado pela tirania dos relógios (tempo uniforme) das sociedades modernas, e só podemos ir no sentido escrito por McLuhan (1968, p. 182), 
“o relógio arrancou o homem do mundo que ritmava o retorno das estações tão completamente quanto o alfabeto o liberou da magia ressonante da palavra e do abismo tribal".

Escreve ele ainda, "a pluraridade dos tempos sucede a uniformidade do tempo". Vivemos, então, uma mutação considerável de uma socialidade fundada sobre a concatenação das marginalidades (Maffesoli), tempo de sínteses e de sincretismo amplificado pela aceleração das trocas na numerosfera ou era do digital: e eis que McLuhan (1968, p. 117) escreve que "nossa civilização especializada e fragmentária de estrutura centro-periférica sofre uma reorganização instantânea de seus fragmentos especializados em um todo orgânico" e descreve uma aceleração que tende ao infinito, uma implosão instantânea, uma "fusão do espaço das funções", quando nossos sistemas nervosos se prolongam em satélites; e ele ainda não previu tudo, como quando as biotecnologias participam da destruição das identidades, "quando o desenvolvimento de próteses sofisticadas permitidas pela informática e o recurso de materiais saídos das nano tecnologias conseguem tornar precárias as fronteiras entre o vivente e a máquina" (Besnier, 2010, p. 155). Esta crítica da Modernidade é estabelecida em Michel Freitag (2002, p. 45),

se a Modernidade representou na história da Sociedade um momento que permite ultrapassar... as únicas relações de força e de instituir sobre uma base reflexiva a coletividade, esta construção grandiosa marcou seus limites [...] se o individualismo liberal e o racionalismo abstrato são um momento negativo da dialética histórica, pois liberam a consciência reflexiva e crítica dos indivíduos, eles devem ser, por sua vez, criticados por sua insuficiência." 
O que de uma certa forma recicla, ao renovar a contribuição da Tradição.

\section{Qual ensinamento para nossos sistemas culturais?}

\section{A questão Oriente-Ocidente}

As sociedades mediterrâneas, de fortes tradições culturais, ao mesmo tempo pertencem a uma modernidade triunfante por sua ancoragem industrial (primeira e segunda Revolução Industrial (Raymaond, 1962)) e se encontram localizadas no cruzamento de influências culturais que vêm a se interceptar, o que traz a questão bastante atual sobre as relações entre culturas ocidentais e orientais, problema que, aliás, não é novo.

René Guénon, filósofo nascido em Blois, em 1886 e morto no Cairo, em 1951, atraído pelas epopeias orientais, estabeleceu com lucidez a questão das relações entre Oriente e Ocidente, e isto a partir de sua descoberta, por trás da existência das religiões, da "história interior e escondida que anuncia a aurora da Grande Luz". Testemunha da crise do mundo moderno em $O$ reino da quantidade e dos signos dos tempos, ele denunciou a ideia de progresso infinito e lembrou que não temos mais a menor ideia de certas ciências cultivadas na Idade Média ocidental. Invertendo as relações de diversas ordens, o mundo moderno ocidental provocou uma diminuição da ordem intelectual em benefício da ordem material. Sua obra Oriente e Ocidente concentra-se nas características específicas das buscas orientais desta pesquisa e opõe uma ciência ocidental, que analisa e dispersa, ao conhecimento oriental, que concentra e sintetiza. É assim que, aquilo que os ocidentais chamam de progresso é, para os orientais, mudança e instabilidade. A crescente e constante multiplicação, no Ocidente, das especialidades e da divisão do trabalho tem base em uma verdadeira miopia intelectual, pois, longe de aprofundar e estender seu domínio, nossa ciência divide o problema, o subdivide, e vê seus objetos escaparem na atomização de seus componentes. No Oriente, ao contrário, para Guénon, todas as ciências têm uma base tradicional, sempre ligada a 
certos princípios: "elas expressam uma certa ordem das coisas, são o reflexo de uma realidade superior imutável, da qual participa necessariamente tudo aquilo que possui qualquer realidade". Porque o conhecimento é a compreensão da ordem universal. Na Idade Média, apontava Guénon, a maior facilidade que a civilização ocidental tinha por meio desses locais de encontro que eram Al Andalus, a Sicília Normanda, o Oriente Médio franco - era se relacionar com as organizações orientais que trabalhavam com a ordem intelectual pura.

Gilbert Durand (1959, p. 151) retoma em seus ativos essa reflexão. De fato, estima ele, "objetivação, causalismo lógico e generalização constituem o grande modelo do racionalismo dedutivo de toda ciência ocidental". E chama à implantação de um terceiro termo, "o intelecto agente", ainda denominado imaginal por Henri Corbin, abandonado pelos ocidentais desde o que ele chama de catástrofe metafísica do Ocidente. Enquanto o século XII foi um século de ouro, onde se equilibravam voces e res, abordagens sagradas e abordagens profanas, Durand vê, no final do século XII, o mundo do res se emancipar do voces, quando a reflexão ocidental "se libera da tradição órfica e de todo acesso à transcendência [...] nega toda efetividade do mundo dos mitos". Aqui confluem averroísmo tomista e ambições temporais do papado, como base de luta do sacerdócio do império. Ele oporá, à abordagem objetivante ou reificante, uma abordagem compreensiva, baseada na postulação de um mundo intermediário onde "as contradições deixam de ser percebidas contraditoriamente" (Breton).

Um grande mito estrutura o pensamento ocidental, motor do destino faustiano do Ocidente, o mito da objetividade científica que pode apenas reforçar a indiferença. Sob um ponto de vista mecanicista e determinista do Universo, ele produz "o homem alienado" no rompimento entre sagrado e profano, em nome de uma lógica binária que abandona toda relação simbólica baseada, ela própria, no trinitário. Essa 
supremacia decorre da explicação histórica, da onipotência dos fatos, justificando todas as perseguições e fanatismos já que somente uma casta, a do clero, da qual os universitários são os herdeiros instituídos, possui o poder da verdade em nome da objetividade científica.

Considerado como o século do positivismo, o século XIX irá redescobrir o Buda e os estudos orientais (Eugéne Burnouf (1801-1885), Sylvain Lévi (1863-1935), Emile Guimet (1831-1916)) e também os românticos que redescobrem a Idade Média, a arte gótica e o Oriente. A relação entre o Oriente e o Ocidente é, de fato, de um assunto central na literatura do século XIX. Alfred de Vigny tem o espírito ocupado por Buda, Edouard Quinet e Hippolyte Taine aproximam as duas religiões, um novo sopro corre sobre os estudos orientais.

A teosofia (Delalande, 2007), no fim do século, toma o Ocidente. Helena Petrovna Blavatsky (1831-1891) funda a Sociedade Teosófica (S.T.) em Nova York, em 1875. Instalada em Adyar, na Índia, perto de Madras, em 1883, ela proporciona um ensino que é baseado em uma crença na evolução do indivíduo em direção à perfeição suprema através de vidas sucessivas (karma). Jiddu Krishnamurti apresenta a síntese mais viva desta corrente, ele inspira ainda hoje diversos pedagogos que trabalham no domíno da educação, tal como René Barbier, que trabalha há 30 anos na Univesidade de Paris 8, onde fundou o GREK (Grupo de Pesquisas e de Estudos sobre Krishnamurti). Em 1910, aos 15 anos, Krishnamurti publicou seu primeiro livro Aos pés do Mestre. Cidadão do mundo, ele viaja bastante para ensinar seu pensamento. Ele morreu em 17 de fevereiro de 1986, nos Estados Unidos, perto dos 91 anos. Seu ensinamento é fora do comum, um verdadeiro questionamento "oriental" sobre o sentido da educação, em função da finalidade de despertar um perfil de ser humano próprio do nosso tempo. O processo educativo para Krishnamurti é justamente essa faculdade de se abrir ao mundo sensível, natural e social, no seio de uma atenção vigilante. O ensino que ele 
proporciona deve ser recebido em profundidade e com um verdadeiro espírito crítico. É a faculdade inteligente do outro que ele se dirige, pois “o entendimento só vem para aqueles que conhecem a si mesmos". O que Krishnamurti busca em seu interlocutor é um "autor", o criador de si mesmo, não um "seguidor", um discípulo: uma pessoa que se autoriza a se apropriar, de uma maneira duvidosa e experiencial, de uma informação essencial para seu próprio futuro, mesmo que essa nova consciência de si, subitamente reconhecida, faça desaparecer a ilusão de um eu existencial e intencional separado do mundo. "Faça a experiência" é sua palavra de ordem, compreendendo, por esse termo, uma situação da vida quotidiana, e não a utilização de um dispositivo excepcional. A postura do magistrado é, assim, questionada por Krishnamurti (p. 96):

São os ensinamentos que contam, não o instrutor que os transmite. [...] E a verdade não é de país nenhum, de nenhuma fé. Porque o verdadeiro mestre não é aquele que ergueu uma organização impressionante, mas aquele que, por ser rico internamente, não pede nada para ele mesmo".

\section{Do Oriente à educação moderna no Ocidente}

Este programa se encontra precisamente, depois de dois séculos, com aquele da Nova Educação e dos movimentos da Educação Permanente. René Barbier enfatizou justamente as convergências:

- A ideia de uma sensibilidade como valor a redescobrir;

- A importância da meditação;

- O reconhecimento da relatividade do tempo e do espaço. 
Assim a Nova Educação, corrente pedagógica que defende o princípio de uma participação ativa dos indivíduos em sua própria formação, declara que a aprendizagem, antes de ser uma acumulação de conhecimentos, deve ser um fator de progresso global da pessoa. Uma das instâncias de mediação desenvolvidas pela Nova Educação é a estrutura grupal. Ao contrário de uma educação destinada somente aos indivíduos, ela comporta uma dimensão coletiva profundamente instauradora do laço social. Encontramos aqui uma dimensão mais antiga da evolução societal, enquanto a Modernidade deu ênfase ao indivíduo soberano.

No fundo, podemos nos perguntar se a Nova Educação não se origina em uma tradição trifuncional hindu-europeia, garantindo aos grupos sociais seu equilíbrio pela complementaridade das funções sociais (laboratores, equites, oratores), bem discerníveis da maior parte de nossos mitos e epopeias, como estabeleceu Georges Dumézil (1966). Ela tenta, assim, corrigir a tentação de uma pedagogia individualizante proveniente das instituições dominantes (igreja, universidade) que impunham seus dogmas, sua doxa. E isso aconteceu em uma época positivista, que só via a salvação individual na adesão ao mito do progresso com base na lógica binária. Para além de uma pedagogia "moderna", centrada no indivíduo, a Nova Educação e a Educação Popular ou Permanente têm suas raízes tanto nas metafísicas do Iluminismo como nas correntes mais undergrounds, ligadas ao aporte das tradições orientais, confortadas por uma postura ao mesmo tempo compreensiva e hermenêutica, que têm seus modelos educativos em outras culturas, espécies de contraculturas ao mesmo tempo espiritualistas e tribais.

\section{Pós-Modernidade: educação para o grupo e as tradições}

E é aqui que se encontram as histórias orientais e ocidentais.

Na Bíblia, os principais personagens têm consigo "associados" os doze chefes das tribos, os doze discípulos de Cristo, recrutados em meio ao povo... Conhecemos 
também os doze pares da França... O número doze, relacionado pelos esotéricos ao décimo segundo arcano, messias ou Holocausto, significa o sacrifício do indivíduo em benefício do coletivo, necessidade de salvação do universo, ele é, nessas manifestações, a representação da humanidade como ponto de apoio do messias (Marcotoune, 1955), do qual a cadeia de iniciação é portadora. Pois o mundo dos doze signos zodiacais é a esfera de aplicação desse sacrifício. É aqui que a matéria recebe a impulsão necessária à sua renassença espiritual. Sabemos ainda que a música chinesa mais antiga havia adotado o sistema duodecimal e que os budistas reconheciam doze causas de existência.

O número doze está igualmente presente na tradição islâmica: ímãs duodecimais, doze planetas, doze meses no calendário de Hégira... No Islã, os companheiros do profeta são numerosos, reconhecidos por ter frequentado e transmitido sua palavra, eles são os primeiros na cadeia de transmissão dos hadices.

Na sociedade, é indispensável que os indivíduos se reúnam em centros de interesse induzidos pelo sensível, que ultrapassem suas ocupações individuais. Esta ligação com os interesses do grupo é fundadora da moral na medida em que a atividade se socializa e se regula dentro do grupo, a encontramos ainda na educação companheira.

A Nova Educação organiza essa transição para uma época onde somente aqueles que são capazes do nomadismo, de vagabundagens iniciáticas, do reencantamento do mundo (Michel Maffesoli) estarão suficientemente armados para enfrentar os novos tempos. Como escreve o sociólogo Georges Balandier:

O imaginário levado pelo fluxo ininterrupto das imagens e das figuras que o manifestam se alimenta ainda de temas antigos: aqueles que o 
reestabelecem em uma duração e o aliam aos mitos cujas significações continuam vivas, e aqueles que ressurgem nos vazios que o homem imaginante de seu tempo não consegue preencher. E todos os períodos de transição revelam este retorno em direção às fontes primeiras, em direção aos mitos do começo, em direção aos saberes escondidos e protegidos.

(Balandier, 1994, p. 31).

Neste sentido, devemos assumir a ideia nova de uma cultura nova, baseada em uma pedagogia do imaginário em atos e, ainda, nas grandes imagens que estruturam, de maneira transversal, nossos espaços culturais, como na utilização indispensável das tecnologias e redes da Modernidade, novos espaços em que temos que investir enquanto nossos parceiros, estudantes, alunos, auditores, atores culturais, deles já se apropriaram!

\section{Conclusão}

A perspectiva intercultural determina uma nova era da comunicação educativa, no encontro da função fantástica com um retorno prolífico das imagens em interação constante, gerando um exuberante enxame que encanta o pensamento da sequência temporal, quando o ser muda de campo, quando a vocação do espírito é insubordinação à existência e à morte, e a função fantástica se manifesta como o chefe desta revolta (Durand, 1969).

Vivemos agora as faces do tempo que ultrapassam as precedentes na forma englobante do ícone, "erguendo contra as faces do tempo o poder de nos erguermos contra a podridão da morte e do destino" (Durand, 1969, p. 470), nos conduzindo a um conhecimento profundo e intuitivo do processo criador, da vida em sociedade (McLuhan, 1968). 
Mudança de consciênca e dos modos de ação, dinâmicas sociais planetárias neste começo de milênio, quando o centro está por tudo e os efeitos culturais são incontáveis (Ferguson, 1980, p. 225). É o tema da emergência, desenvolvido por Jean Michel Besnier, enquanto a ciência e a técnica modernas perderam o ideal cartesiano do domínio que os definia, pois eis que as utopias pós-humanas oferecem a perspectiva do todo outro (Besnier, 2010).

Nós devemos assumir uma nova ontologia, de "novas figuras do pensável" (Castoriadis, 1999, p. 281) como capacidades de criação, de vida baseada no ser, como "surgimento permanente que sai de um abismo sem fundo", ou seja, uma outra forma de pensar o mundo propriamente instituinte.

Assim, as mutações que ocorrem nos imaginários nos incitam a representar de forma "mais feliz e fortuita" as significações imaginárias sociais, que nascem do fluxo incessante das interações ocorridas nas sociedades agora plurais, onde o distante tornou-se tão próximo.

Nós podemos fazer a aposta razoável que as sociedades educativas que saberão ao mesmo tempo cortar suas raizes, cultivar as modalidades de educação fundadas na comunidade e na tradição e levar com elas, paradoxalmente sem negá-las, a distância crítica que a Modernidade nos ensinou, enquanto afronta as mutações do ciberespaço e do que chamamos "hoje de pós-humanismo", se colocarão em uma perspectiva aberta e necessariamente dinâmica, pois será baseada em interações reais. Uma outra educação, que tire lições desta complexidade, que seja plural, instável e combine, paradoxalmente, dinâmica de grupo, grafosfera e numerisfera, graças às novas tecnologias, encontrará aí sua força e razão de ser.

Pois é verdade, como escreveu Gilbert Durand (1979, p. 221), que "nossa Ciência Humana se baseia primeiramente no reconhecimento da complexidade extrema e oriunda de uma lógica do antagonismo do objeto humano". 


\section{REFERÊNCIAS}

ARDOINO, Jacques. Education et politique. Paris: Anthropos, 2001.

. Propos actuels sur l'Education. Paris: L'Harmattan, 2004.

ARON, Raymaond. Dix huit leçons sur la société industrielle. Paris: Gallimard, 1962.

AURELL, Martin. Le chevalier lettré. Paris: Fayard, 2011.

BALANDIER, Georges. Le dédale. Paris: Fayard, 1994.

BERTIN, Georges. La Pierre et le Graal. Paris: Véga, 2006.

. La quête du saint Graal et l'Imaginaire. Condé sur Noireau: Éditions Charles Corlet, 1997.

BESNIER, Jean-Michel. Demain les post humains. Paris: Fayard, 2010.

CASTELLS, Manuel. La Galaxie Internet. Paris: Fayard, 2001.

CASTORIADIS, Cornélius. La montée de l'insignifiance, les carrefours du labyrinthe IV. Paris: Le Seuil, 1996.

. Figures du pensable, Paris: Le Seuil, 1999.

CAZENEUVE, Jean. Dix grandes notions de sociologie. Paris: Le Seuil, 1991.

CERTEAU, Michel de. Les Cultures Populaires. Paris: Privat. 1971.

CHAUNU, Pierre. La civilisation de l'Europe des Lumières. Paris: Arthaud Flammarion, 1982.

DELALANDE, Marie José. Le mouvement théosophique en France, 1876-1921. Thèse de doctorat d'histoire contemporaine. Université du Maine, 2007.

DEBRAY, Régis. Introduction à la médiologie. Paris: PUF, 2000.

DUMEZIL, Georges, Mythe et Epopée. Paris: Gallimard, 1966.

DURAND, Gilbert. Science de l'homme et tradition: le nouvel esprit anthropologique. Paris: Berg International, 1979.

. Les structures anthropologiques de l'Imaginaire. Paris: Dunod, 1969.

FERGUSON, Marylin. The aquarian conspiracy. Los Angeles: Tarchet, 1980.

FREITAG, Michel; BONNY, Yves. L'oubli de la société: pour une théorie critique de la Modernité. Québec: Presses Universitaires de Laval, 2002.

D’ALLONDANS, Thierry Goguel. Rites de passage, rites d'initiation. Québec: Presses Universitaires de Laval, 2002.

GUENON, René. La crise du monde moderne. Paris: Gallimard, 1973. 
GUENON, René. Orient et Occident: le règne de la quantité et les signes des temps. Paris: Gallimard, 1945.

GUYONWARC'H, Christian. Les Druides. Rennes: Ouest-France-Université, 1986.

KRISHNAMURTI, Jiddu. La première et la dernière liberté. Paris: Stock,1964.

. De l'Education. Paris: Delachaux et Niestlé, 1972.

LE GOFF, Jacques. La Civilisation de l'Occident médiéval. Paris: Arthaud, 1964.

LERBET, Georges. Dans le tragique du monde. Paris: Edimaf, 2005.

LEVY-BRUHL, Lucien. La mentalité primitive. Paris: Retz, 1976.

MACLUHAN, Marshall. Pour comprendre les médias. Paris: Le Seuil, 1968.

MAFFESOLI, Michel. Elogie de la raison sensible. Paris: Grasset, 1996.

. Le temps des tribus. Paris: Méridiens Klincksieck, 1988.

. L'instant éternel. Paris: Denoël, 2000.

. La violence totalitaire. Paris: Desclée de Brouwer, 1979.

MARCOTOUNE, Serge. La science secrète des initiés et la pratique de la vie. Paris : Champion, 1955.

MORIN, Edgar. Sociologie. Paris: Fayard, 1974.

RIESMAN, David. La Foule solitaire. Arthaud. 1984.

VINCENT, Frédéric. De L'imaginaire initiatique: les mythes postmodernes ou le dépassement de l'existence tragique. Thèse de doctorat de sociologie. Université Paul Valery Montpellier, 2010.

\section{NOTAS}

1 Este artigo resulta do prolongamento de uma reflexão aberta por Cristiane Freitas, no Seminário Internacional que ela organizou em Porto Alegre, nos dias 18 e 19 de outubro de 2010: Imagens do espaço... Tradução de: Helena Stigger, Doutora em Comunicação Social pelo Programa de Pós-Graduação da Faculdade de Comunicação da Pontifícia Universidade Católica do Rio Grande do Sul. Bolsista de PNPD (Programa Nacional de Pós-Doutorado) pelo PPG-COM da PUCRS. <lenastigger@acad.pucrs.br>. Roberta Coelho Barros, Doutoranda no Programa de Pós-Graduação em Comunicação Social da PUCRS.<robertabarros@gmail.com>.

2 Riesman pertence à segunda geração dos sociólogos da Escola de Chicago que conta também com Erwin Goffmann et Becker.

3 N.T. Compagnons Bâtisseurs é uma organização da juventude belga que propõe aos jovens de 14 a 30 anos projetos de vountariado organizados na Bélgica e pelo mundo.

4 Source infos plus Gabon (2011). 